\title{
Serum imbalance between the extracellular matrix metalloproteinases (MMP-2 and MMP-9) and their tissue inhibitor (TIMP-1) in patients with food and airborne allergy
}

\author{
A Kuźmiński', M Przybyszewski, M Graczyk, M Żbikowska-Gotz, Z Bartuzi \\ From Food Allergy and Anaphylaxis Meeting (FAAM 2013) \\ Nice, France. 7-9 February 2013
}

\section{Background}

Comparison of the concentration of MMP-2 and MMP9 and TIMP-1 in patients with food and airborne allergy as compared to patients without allergy.

\section{Methods}

The study was performed in 80 individuals: 60 patients with exacerbation of allergic disease (30 with food allergy and 30 with airborne allergies) and 20 healthy subjects. We examined the serum concentrations of soluble forms of MMP-2, MMP-9 and TIMP-1. Determination of these parameters was performed by ELISA. For MMP-9 and TIMP-1 was used kit from Bender MedSystems, for MMP-2 of RayBiotech. A statistical study results was performed using the computer program STATISTICA 9.1.

\section{Results}

The concentrations of sMMP-2 and-9 in the groups of patients with food and airborne allergy and control groups were, respectively, $153,8 \pm 97,1$ and $198,8 \pm 51,4 \mathrm{ng} / \mathrm{ml} ; 136,3$ $\pm 41,2$ and $184,9 \pm 38,8 \mathrm{ng} / \mathrm{ml}$, and $119,5 \pm 12,5$ and 121,6 $\pm 25,5 \mathrm{ng} / \mathrm{ml}$. sMMP-2 demonstrated statistically significant differences between the group with food allergies and the control group $(p=0.0309)$, no significant differences between the group of airborne allergy and the control group, as well as between groups of airborne and food allergies (for $\mathrm{p}=0.4225$ and $\mathrm{p}=0.1473$ ). Differences of sMMP-9 levels were significantly higher in the group of airborne and food allergies than in the control group

Department of Allergology, Clinical Immunology and Internal Medicine Collegium Medicum in Bydgoszcz, Nicolaus Copernicus University in Toruń, Bydgoszcz, Poland (both $\mathrm{P}=0.0000$ ). There was no significant difference between the group of patients with airborne and food allergy ( $p=0.3952)$. The concentrations of sTIMP-1 in groups of patients with food allergy and airborne were significantly higher than those in the control group (respectively $\mathrm{p}=0.0000$ and $\mathrm{p}=0.0003$ ) and were in the group with food allergies $164.3 \pm 59.2 \mathrm{ng} / \mathrm{ml}$; airborne allergy \pm $145.450 .1 \mathrm{ng} / \mathrm{ml}$, whereas in the control group $92.4 \pm 26.7$ $\mathrm{ng} / \mathrm{ml}$. There was no statistically significant difference sTIMP-1 concentrations between the group of patients with airborne and food allergy ( $\mathrm{p}=0.2458)$.

\section{Conclusion}

MMP-2 and MMP-9 and TIMP-1 were significantly higher in patients with food allergy than in the control group. A similar observation (except for concentrations sMMP-2) also applies to a group of patients with airborne allergy. The results of this study suggest an important role of MMPs and TIMPs in the pathogenesis of allergic inflammation.

\section{Disclosure of interest}

None declared.

Published: 25 July 2013

\section{doi:10.1186/2045-7022-3-S3-P50}

Cite this article as: Kuźmiński et al:: Serum imbalance between the extracellular matrix metalloproteinases (MMP-2 and MMP-9) and their tissue inhibitor (TIMP-1) in patients with food and airborne allergy. Clinical and Translational Allergy 2013 3(Suppl 3):P50. 